by ammonia water, the rate of hydrolysis is greatly increased by the presence of copper in all the cases examined.

5. No effect is observed in the case of halogen substituted in the benzene nucleus.

6. A color test is described for tetrachloroethylene.

Amgerst, Mass.

\title{
XIII. MOLECULAR REARRANGEMENTS IN THE CAMPHOR SERIES. THE DECOMPOSITION PRODUCTS OF THE METHYL ESTER OF ISOAMINOCAMPHONANIC ACID. A NEW REACTION INVOLVING THE FORMATION OF THE METHYL ETHER OF A HYDROXY ACID. By WILliam A. Noyes aNd GLENN S. SKINNER. ${ }^{1}$ Received September 4, 1917.
}

Several years ago, L. R. Littleton ${ }^{2}$ and one of us were engaged upon the study of the decomposition of isoaminocamphonanic acid with nitrous acid. Cis-camphonololactone was the only product identified. We have undertaken the study of the decomposition of the methyl ester with the intention of separating the products by fractional distillation under diminished pressure. The products that would normally be expected are a methyl ester of a hydroxy (trans-camphonolic) acid with hydroxyl in place of the amino group and a methyl ester of a $\Delta_{3}$ unsaturated acid containing a gem methyl. Neither of these products has been found but instead at least six compounds involving rearrangements. Our results show that the methyl ether and methyl ester of cis-camphonolic acid and the methyl esters of lauronolic acid, I,2,2-trimethyl-I-carboxycyclopentene-4, cis $x, 2,3$-trimethyl-2-hydroxy-I-cyclopentanoic acid, and a secondary $\beta$-hydroxy acid are formed. The method of preparing the hydrochloride of methyl isoaminocamphonanate and the nature of the decomposition products will be most clearly understood from the following diagram:

The $d$ - and $l$-camphoric acids ${ }^{3}$ allow racemization of the secondary but not of the tertiary carboxyl when sufficient strain is produced in the molecule by heat, being converted respectively to $l$-isocamphoric and $d$-isocamphoric acids in 50\% yield if equilibrium is established. The hydroxy compound that would ordinarily be expected in this decomposition is the methyl ester of trans-camphonolic acid, but no trans compound has thus far been identified. It is not clear whether the cis compounds we have

1 An abstract of a thesis submitted by Mr. Skinner in partial fulfillment of the requirements for the Degree of Doctor of Philosophy in the University of Illinois.

2 THIS Journal, 35, 75 (1913).

Ber., 27, 200.5 (I894). 


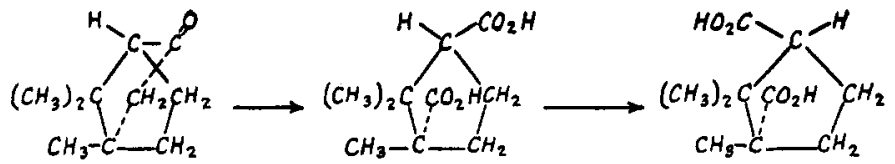

$d$-camphor $d$-Camphoric Acid

l-Isocamphoric Acid
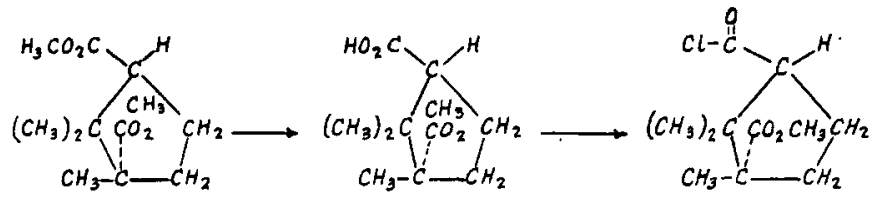

Dimethyl l-Isocamphorate

$\beta$-Methyl l-Isocamphorate

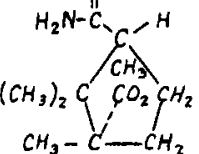
$\mathrm{H}_{2} \mathrm{~N}-\mathrm{C}-\mathrm{H}$

-Methyl l-Iso-

Methyl l-I9o-

camphoramidate

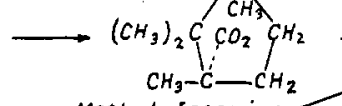

Methyl Isoamino camphongarate

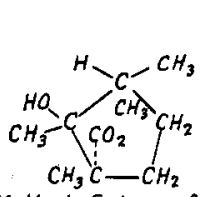

Methyl Ester of

Acid $M \cdot P=101-1 \mathrm{P}^{\circ}$
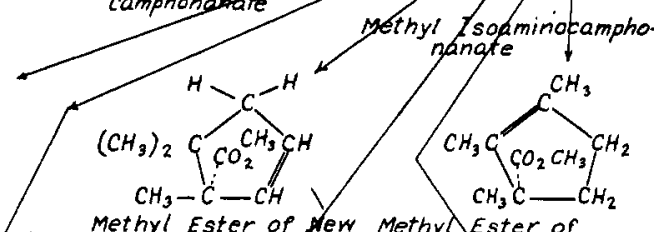

Methyl Ester of Aew Methy Ester of

Methyl Ester of
unsaturated Acil Methy Ester of
Laurondic Acid

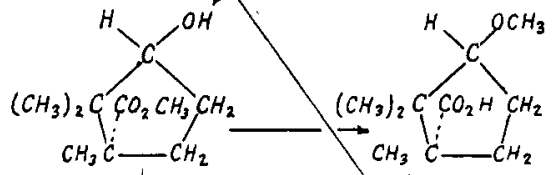

Methyl Ester of

Methyl Ester of acid MethxV Ether of

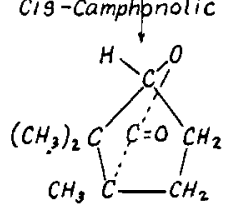

Acid Cis-agmphonolic Acid

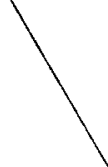

other Esters of

Hydroxy Acids

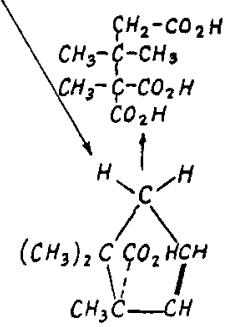

Cis-Camphonololactone
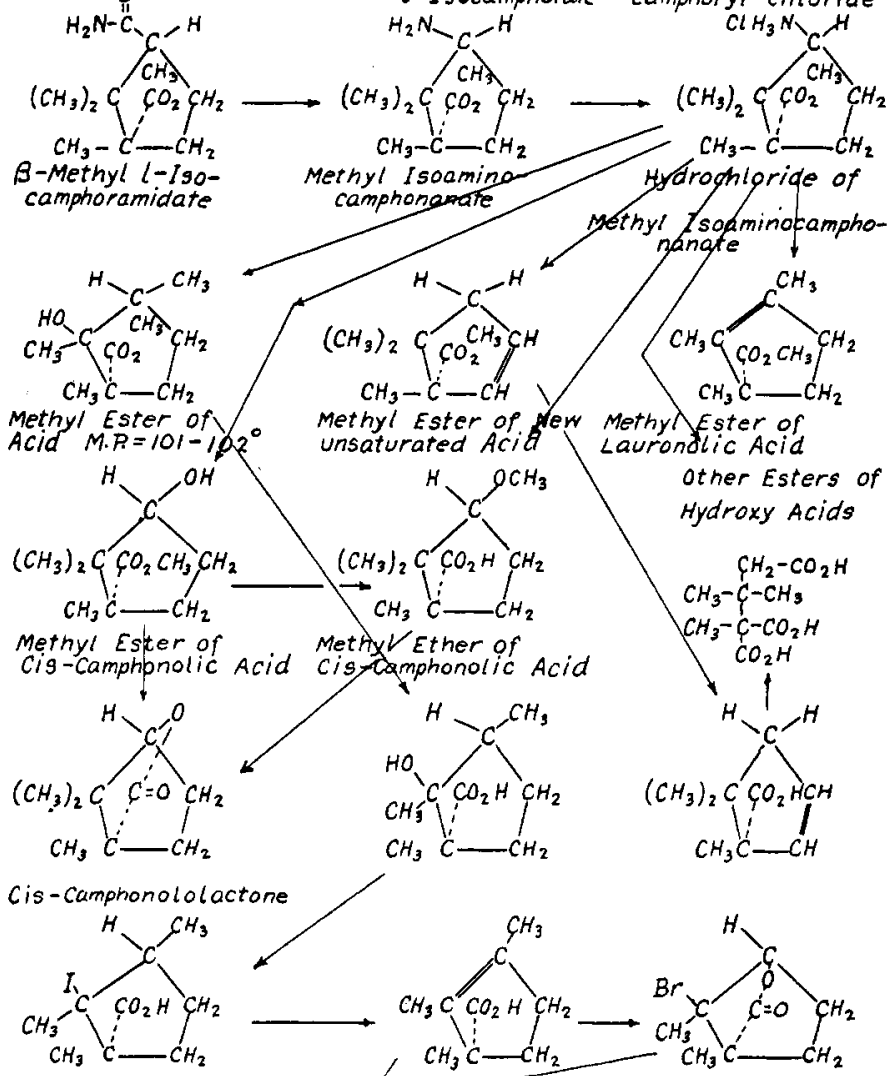
found are formed by racemization or by a Walden inversion since unsaturated compounds are also formed and it is possible that these result from intermediate transhydroxy compounds.

A cis structure has been assigned to cis-camphonolic acid since it gives a lactone by heating alone without a dehydrating agent and has a positive rotation. Furthermore the following facts furnish very good evidence for the cis configuration:

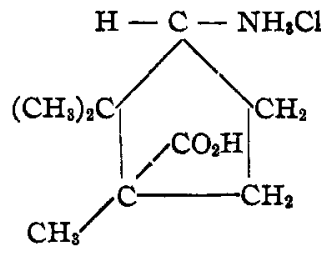

Hydrochloride of aminocamphonanic acid. $\alpha_{D}=25.0^{\circ}$.

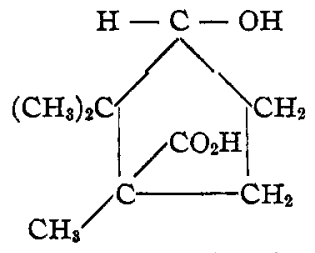

Cis-camphonolic acid. $\alpha_{D}=29.7^{\circ}$.

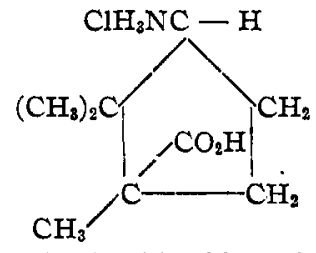

Hydrochloride of isoaminocamphonanic acid. $\alpha_{\mathrm{D}}=-28.8^{\circ}$.

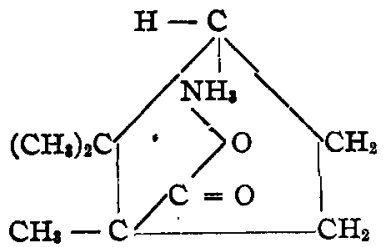

Aminocamphonanic acid $\alpha_{\mathcal{D}}=-29.2^{\circ}$.

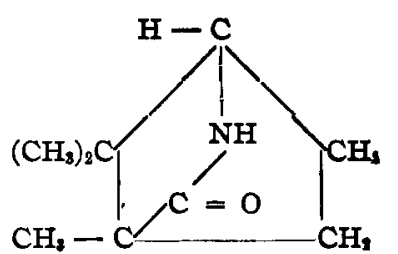

Anhydride of aminocamphonanic acid.

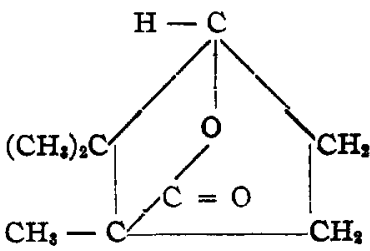

Cis-camphonololactone.

$$
\alpha_{\mathbb{D}}=-22.3^{\circ} \text {. }
$$

A comparison of the rotations of the above affords an excellent illustration of the general effect of ring formation upon the rotation of these compounds. If the acid is dextro-rotatory and has a tertiary carboxyl then the rotation of the cyclic derivative will be more negative, while it will be more positive if the carboxyl is secondary. The relation between cis-camphonolic acid and cis-camphonololactone is in accord with that between aminocamphonanic acid and its cyclical derivatives. The acid for this reason must have the cis-configuration.

The formation of the methyl ether of cis-camphonolic acid in this decomposition has no parallel in the literature so far as we are aware. The ether acid is the only acid substance formed and, therefore, the change 
must be intramolecular, that is, the methyl group does not detach itself except as a free radical, which immediately shifts to another position.

In the nitrite decomposition of an aliphatic amine the alcohol produced often has the hydroxyl group on a carbon atom different from the one to which the amino group was originally linked. Henryl has found the following results and concludes that this change takes place to a greater extent as the number of methyl groups on the carbon atom is greater:

I. $\mathrm{CH}_{3}-\mathrm{CH}_{2}-\mathrm{CH}_{2}-\mathrm{NH}_{2}$
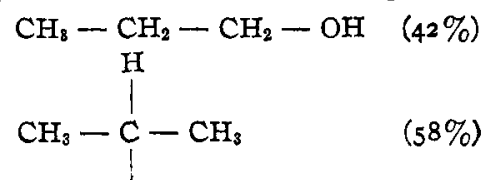

2. $\underset{\mathrm{CH}_{3}}{\stackrel{\mathrm{H}}{\mathrm{CH}_{3}} \succ} \mathrm{C}-\mathrm{CH}_{2}-\mathrm{NH}_{2}$
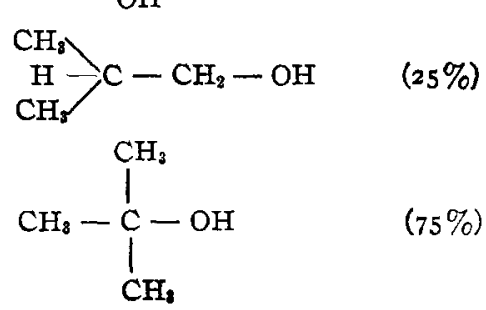<smiles>CC(C)(C)CN</smiles><smiles>CCC(C)(C)O</smiles>

This would lead one to suspect that the hydroxyl would go in large part to the carbon bearing the gem methyl, but this could only be accomplished by the shifting of one of the methyl radicals and a tertiary hydroxy acid containing a $\mathrm{I}, 2,3$-trimethyl grouping would result.
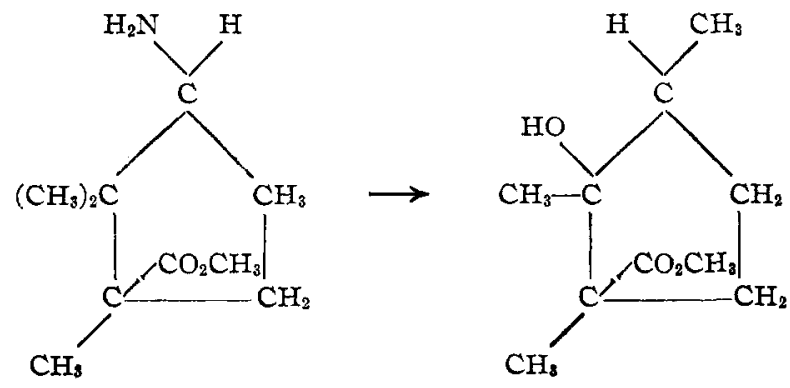

${ }^{1}$ Compt. rend., 145, 899, I 247 (1907). 
We have found that such a compound is formed and also have some evidence that a compound having a secondary hydroxyl on the other $\beta$-carbon is formed in this decomposition.

The methyl ester of a $\gamma, \delta$ unsaturated acid would be normally expected. This should give camphoronic acid on oxidation but no camphoronic acid was obtained by the oxidations of the unsaturated acids which are formed. If it is true that the hydroxyl and methyl radicals exchange places it is reasonable to think that the double bond might also shift in the same direction. We have found this to be the case, as both lauronolic acid and a new tertiary $\Delta_{2}$ acid are formed.

A $\beta, \gamma$ unsaturated acid by heating with alkalies is changed to an $\alpha, \beta$ unsaturated acid. In this series it had been definitely shown that a $\gamma, \delta$ ( $l$-campholytic) unsaturated acid by treatment with dilute acids rearranges to an $\alpha, \beta$ (isocampholytic) unsaturated acid. However, in the case of the $\gamma, \delta$ unsaturated acid that would normally be expected from isoaminocamphonanic acid, a shift of the double union to the $\alpha, \beta$ position would not be expected by analogy since this carboxyl is tertiary. The possibility then remains that the shift would be to the $\beta, \gamma$ position and we have confirmed this by experiment.

The hydrocarbon which was obtained from our unsaturated acid has the same boiling point as laurolene. In order to determine whether the two are identical we undertook a study of the refractometric constants of both hydrocarbons. The laurolene used was not as pure as might be desired but the result leaves no doubt as to the identity of the two substances.

Eykman $^{1}$ (1906) predicted the constitution of laurolene, which was afterward confirmed by chemical methods, on the basis of refractometric studies. According to his view a ring structure, in which one double bond is located, is regarded to be the equivalent of a single side chain, while a compound (semicyclic) containing a double bond between two carbon atoms, only one of which is a member of a ring, is to be considered the equivalent of two side chains. In calculating the dispersion from refractive indices by the three hydrogen lines $C, F$ and $G^{\prime}$ for laurolene and hydrolaurolene, he found that the differences were exactly accounted for by the summation of the effects of one double union and three side chains, these values having been obtained by measurement of compounds of known structure. He considers that laurolene must then contain the $\mathrm{CH}_{3} \mathrm{CH}_{3}$ by chemical methods, our chief interest being a comparison between the

'Chem. Weekblad, 3, 708. Cf. also "Over de Synthese en Struktuur van eenige Lauroleenderivaten," by J. L. Hoving, pp. 29, 64 . 
constants of the laurolene which we obtained from lauronolic acid (I), the hydrocarbon from our unsaturated acid (II) and Eykman's laurolene. The molecular refractive powers were calculated according to the following formulas:

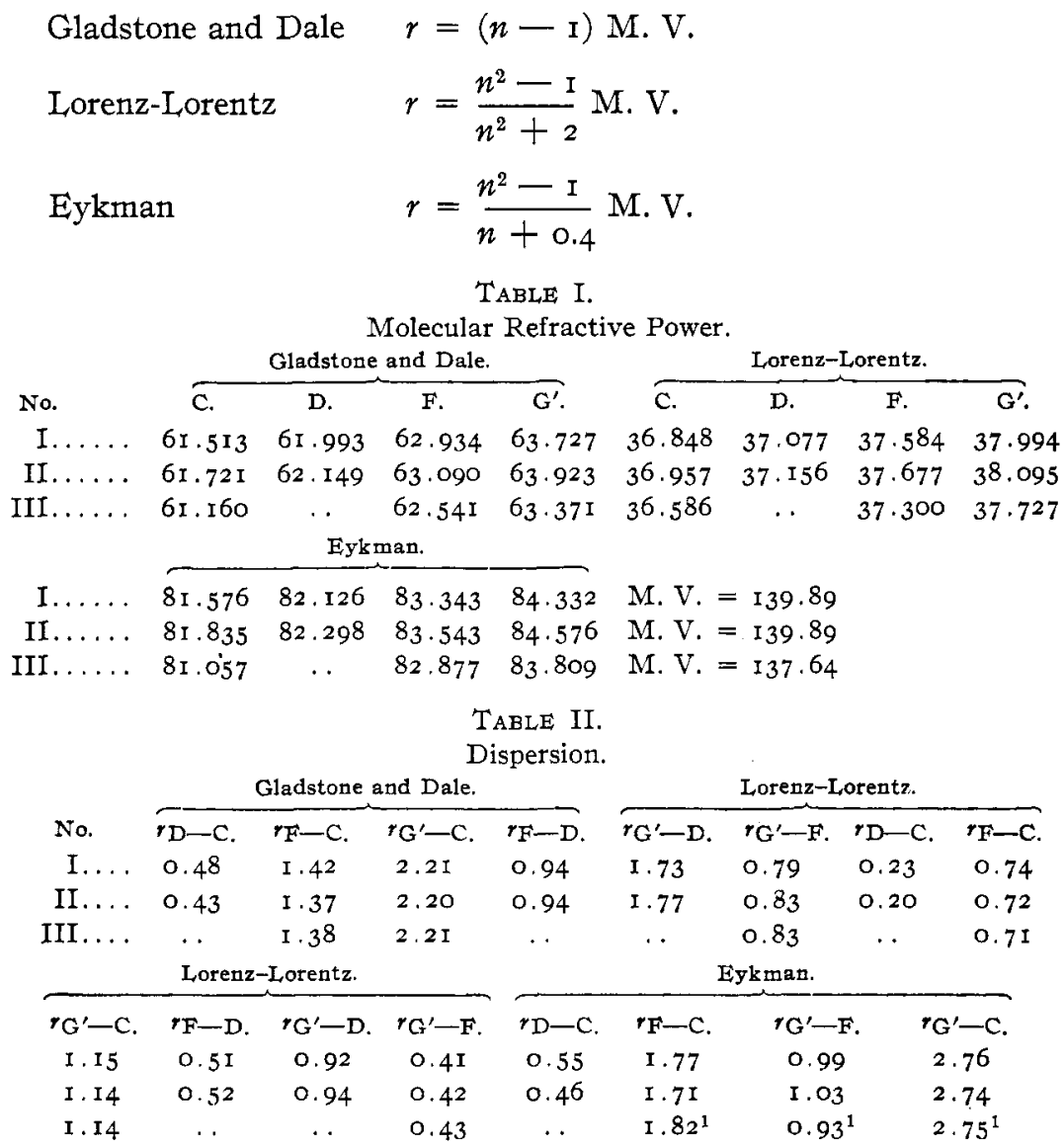

Eykman also calculated the specific refractive power of laurolene from data taken at $80.5^{\circ}$ with results practically identical with those at $17.3^{\circ}$. It is, therefore, allowable to compare results at $25^{\circ}$ with his. The index of refraction for our hydrocarbons increases as the temperature falls. In calculating the molecular volume at $25^{\circ}$ of the laurolene obtained from lauronolic acid the density of the hydrocarbon obtained from the unsaturated acid of the nitrite decomposition was used, since the former was not as pure as the latter.

${ }^{1}$ On page 30 of J. L. Hoving's book the values from Perkin's data are, respectively, $1.71,1.03$ and 2.74 which are in exact agreement with our values, although the figures given on page 60 give the results indicated. 


\section{Experimental Part.}

$l$-Isocamphoric Acid.--This acid was obtained by the method of Noyes and Knight, ${ }^{1}$ in which $d$-camphoric acid is heated in sealed tubes with acetic and hydrochloric acids. A total of $3450 \mathrm{~g}$. has been prepared. In recrystallizing the crude acid it was found that the acid sometimes tended to precipitate as an oil, in which event the material should be treated again with acetyl chloride in order to secure a pure product. It gave the

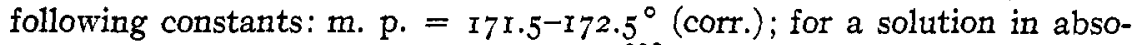
lute alcohol containing $0.09784 \mathrm{~g} . / \mathrm{cc}$., $\alpha_{\mathrm{D}}^{28^{\circ}}=-46.8^{\circ}$.

$\alpha, \beta$-Methyl $l$-Isocamphorate. ${ }^{2}$-Noyes and Littleton obtained this ester by boiling a solution of $200 \mathrm{~g}$. of $l$-isocamphoric acid with $800 \mathrm{cc}$. of methyl alcohol and $80 \mathrm{cc}$. of concentrated sulfuric acid for 48 hours. It was found that by using the materials in this proportion the yield was inappreciable after five hours, but if twice the quantity of sulfuric acid was used the yield was increased to $50-60 \%$ of the theory. A thermometer immersed in the boiling liquid showed that the temperature increases from $71-78^{\circ}$ on account of this modification. The following constants were observed: b. p. $=\mathrm{r} 30^{\circ}\left(8 \mathrm{~mm}\right.$.), $\mathrm{I} 38^{\circ}$ ( $\left.\mathrm{I} 3 \mathrm{~mm}.\right), \mathrm{I} 4 \mathrm{I} .5^{\circ}$ (16 mm.), I $44^{\circ}$ (19 mm.), $146^{\circ}$ (22 mm.); $\alpha_{\mathrm{D}}^{24.5^{\circ}}=-65.5^{\circ}$. For a solution in absolute alcohol containing $0.107 \mathrm{~g} . / \mathrm{cc}$., $\alpha_{\mathrm{D}}^{22^{\circ}}=-66.5^{\circ}$. Some representative experiments are given in the appended table.

\begin{tabular}{|c|c|c|c|c|c|c|}
\hline \multirow[b]{2}{*}{$\begin{array}{l}\text { b-Isocamphoric } \\
\text { acid. }\end{array}$} & \multirow[b]{2}{*}{$\begin{array}{l}\text { Acid } \\
\text { ester. }\end{array}$} & \multicolumn{3}{|c|}{ TABLE III. } & \multirow[b]{2}{*}{$\begin{array}{l}\text { Yield of } \\
\text { acid ester. }\end{array}$} & \multirow[b]{2}{*}{$\begin{array}{l}\text { Yieid of } \\
\text { dimethyl ester. }\end{array}$} \\
\hline & & $\mathrm{CH}, \mathrm{OH}$. & $\mathrm{H}_{2} \mathrm{SO}_{4}$. & Time. & & \\
\hline $300 \mathrm{~g}$. & . & I $200 \mathrm{cc}$. & $240 \mathrm{cc}$ & 6 hrs. & $160 \mathrm{~g}$. & .. \\
\hline 243 & $80 \mathrm{~g}$. & 1300 & 248 & 12 & 82 & . . \\
\hline $5^{8}$ & 242 & 1200 & 240 & 14 & 80 & $900 \mathrm{~g}$. \\
\hline 225 & 80 & 1220 & 244 & 16 & 70 & .. \\
\hline 71 & 70 & 560 & 112 & 14 & 43 & . \\
\hline
\end{tabular}

$\beta$-Methyl $l$-Isocamphorate.--The method of Noyes and Littleton ${ }^{3}$ was used in preparing this ester. It did not crystallize.

$\beta$-Methyl $\alpha$-l-Isocamphoramidate.-The viscous $\beta$-methyl ester was dissolved in a small quantity of absolute ether and a solution containing I65 g. of the ester was slowly added from a dropping funnel to a flask fitted with a reflux condenser and containing $165 \mathrm{~g}$. of phosphorus pentachloride covered with $500-600 \mathrm{cc}$. of petroleum ether (b. p. $=25-40^{\circ}$ ). When the phosphorus pentachloride had disappeared the solution of the acid chloride was added drop-wise to $75^{\circ} \mathrm{cc}$. ammonium hydroxide (sp. gr. 0.90) which was vigorously stirred by means of a mechanical stirrer and kept at a temperature of - $10^{\circ}$ by a freezing mixture of ice and hydro-

1 This Journal, 32, I670 (I9I0).

${ }^{2}$ The tertiary carboxyl of camphoric acid is designated as $\beta$ in this paper. $\alpha$-Camphoramidic acid has the amide group in the secondary carboxyl.

3 This Journal, 35, 78 (IgI3). 
chloric acid. It is important that the temperature be kept low and that the ligroin solution be dilute as the yield is otherwise very poor. The amide was filtered with suction and then dissolved in a small quantity of warm alcohol and filtered from mechanical impurities. It was then precipitated by slowly adding four or five volumes of cold water with stirring. In this manner Ioo $\mathrm{g}$. of a white crystalline product was obtained, which melted at $127^{-1} 128^{\circ}$ (corr.). The specific rotation for a solution in absolute alcohol containing $0.1047 \mathrm{~g} . / \mathrm{cc}$. was $\alpha_{\mathrm{D}}^{28^{\circ}}=-55.4^{\circ}$. Noyes and Littleton found $\alpha_{\mathcal{D}}=-54 . I^{\circ}, \mathrm{m} . \mathrm{p} .=\mathrm{I} 26-\mathrm{I} 27^{\circ}$. It is difficultly soluble in ether. By concentrating the mother liquors the yield was increased to I33 $\mathrm{g}$. or $80 \%$ of the theory.

Methyl Isoaminocamphonanate.-To ro $\mathrm{g}$. of $\beta$-methyl $\alpha$-l-isocamphoramidate was added a solution of sodium hypobromite ( $1.25 \mathrm{~mol}$ ) freshly prepared by aspirating the vapor of ro g. bromine through Ioo cc. of a $10 \%$ solution of sodium hydroxide which was surrounded by ice water. Noyes and Littleton heated the mixture for fifty minutes, but this was found to be unnecessary and undesirable since the saponification of the ester may become appreciable due to such long-continued heating. The contents of the flask should be heated rather slowly on the steam bath for the first two or three minutes, frequently giving the flask a gentle rotatory motion. If the operation is carried out properly a clear solution will result. On further heating the solution becomes turbid, the orange color which is developed instantaneously disappears, and an almost colorless oil separates at the surface. During this part of the operation the contents of the flask should be vigorously shaken in a bath of live steam. The entire time necessary for the completion of the reaction is five or six minutes.

After cooling, the ester was extracted with ether. This solution was then extracted with dilute hydrochloric acid, any unchanged amide remaining in the ether layer. The ester boils at $135^{-1} 3^{\circ}$ (10-22 mm.) and was obtained as a clear mobile oil which had a fishy odor. The specific rotation was $\alpha_{\mathbb{D}}^{26^{\circ}}=-49^{\circ}$. For a solution in absolute alcohol containing $0.105 \mathrm{~g} . / \mathrm{cc} . \alpha_{\mathrm{D}}^{25^{\circ}}=-41.2^{\circ} ; \mathrm{d}_{4^{\circ}}^{25^{\circ}}=1.016 \mathrm{I}$. The ester which was used in the determination of the physical constants was obtained from the hydrochloride which had been crystallized twice from ether, and this from an ester which had not been distilled.

Hydrochloride of Methyl Isoaminocamphonanate.-Gaseous hydrogen chloride was conducted to the surface of an ethereal solution of the amino ester. The hydrochloride crystallized in long, white needles which melted at $179-180^{\circ}$ (corr.). The rotation for a solution in absolute alcohol containing $0.08830 \mathrm{~g} . / \mathrm{cc}$. was $\alpha_{\mathrm{D}}^{25^{\circ}}=-42.2^{\circ}$. Noyes and Littleton found for the monohydrate, m. p. $=177^{\circ}, \alpha_{\mathrm{D}}=-42.03^{\circ}$. The yield was $70 \%$ of the theory calculated on the basis of the amide in the later experiments, 
although at first poor results were obtained and much material was wasted in carrying out the hypobromite reaction.

Decomposition of Methyl Isoaminocamphonanate.-Twenty-five grams of the above hydrochloride were dissolved in Ioo $\mathrm{cc}$. of water. To this solution was added a solution of $8.4 \mathrm{~g}$. (I.I mol) of sodium nitrite in 25 cc. of water. A drop or more, if necessary, of hydrochloric acid was added to start the reaction and the reaction mixture was kept very near room temperature by placing the flask in a dish of water. The reaction was usually complete in 24 hours. The oily product separating at the surface was extracted from the acid solution with ether and the ether extract was shaken with a 10\% sodium carbonate solution to remove the ether acid. The esters were then subjected to fractional distillation under diminished pressure, using a distilling bulb especially designed for the purpose. ${ }^{1}$

It has been found necessary to repeat the work thus far described several times in order to obtain materials in sufficient quantity for study. Below are to be found the results of the fifth and sixth experiments, in which comparatively large quantities of the hydrochloride were used.

Hydrochloride. Wt. of products. Ether acid. Camphonolic Esters of other
ester.

$\begin{array}{llllll}225 \mathrm{~g} . & 144 \mathrm{~g} . & 13 \% & 26 \% & 20 \% & 4 \mathrm{I} \% \\ 345 & 2 \mathrm{i} 6 & 13 & 27 & 20 & 40\end{array}$

Methyl Esters of the Unsaturated Acids. -The fraction boiling at $86-88^{\circ}$ ( $2 \mathrm{r} \mathrm{mm}$.) obtained in one of the earlier experiments in which small quantities of materials were used was analyzed with the following results:

Calc. for $\mathrm{C}_{8} \mathrm{H}_{13} \mathrm{CO}_{2} \mathrm{CH}_{8}: \mathrm{C}, 7 \mathrm{I} .37 ; \mathrm{H}, 9.59$. Found: $\mathrm{C}, 70.78,7 \mathrm{I}, 35 ; \mathrm{H}, 9.47$ 9.32.

The purest sample of the ester is evidently that obtained in the last experiment. Here a product weighing $50 \mathrm{~g}$. and boiling constantly was obtained with the special fractionating apparatus. Our results show that all unsaturated compounds are to be found in this fraction. The ester was obtained as a light colorless oil having a somewhat pungent odor. It gave the following physical constant:

B. p. $=75^{\circ}(9 \mathrm{~mm}),. 78.5^{\circ}(15 \mathrm{~mm}),. \alpha_{\mathrm{D}}^{26.5^{\circ}}=76.6^{\circ}$. For a solution in absolute alcohol containing $0.1043 \mathrm{~g} . / \mathrm{cc} . \alpha_{\mathrm{D}}^{240}=74.4^{\circ}, \mathrm{d}_{4}^{25}=0.9594, \mathrm{~d}_{4}^{20}=0.9637, n_{\mathrm{c}}^{26^{\circ}}=$ I.45454, $n_{\mathrm{D}}^{250^{\circ}}=\mathrm{I} .45755, n_{\mathrm{F}}^{250^{\circ}}=\mathrm{I} .46423, n_{\mathrm{G}}^{25} \mathrm{i}=1.4697$.

Methyl Esters of the Intermediate Hydroxy Acids.-Seventeen hundred grams of $l$-isocamphoric acid yielded $40 \mathrm{~g}$. of a product boiling at II -1 I $4^{\circ}$ (I $8 \mathrm{~mm}$.). Analysis gave the following results:

Calc. for $\mathrm{C}_{8} \mathrm{H}_{14} \mathrm{CO}_{\mathrm{CO}_{3}}^{\mathrm{OH}}: \mathrm{C}, 64.46 ; \mathrm{H}, 9.74$. Found: $\mathrm{C}, 64.5 \mathrm{I}, 64.27,64.55 ; \mathrm{H}$, $9.44,8.96,9.33$.

${ }^{1}$ See the following article. 
Hydrocarbons.-After distilling off the ether from the ethereal solution of the esters, using a Ladenburg distilling bulb, the small amount of residue was distilled at atmospheric pressure in a small bulb. The temperature rose almost immediately to about $200^{\circ}$. As the last traces of ether had been removed at $100^{\circ}$ under a pressure of about $40 \mathrm{~mm}$., it is at once evident that no hydrocarbon was formed in the decomposition.

Methyl Ester of cis-Camphonolic Acid.-This ester when pure boils at $134^{-1} 35^{\circ}$ ( $16 \mathrm{~mm}$.). Analysis of the ester obtained in the fractional distillation gave:

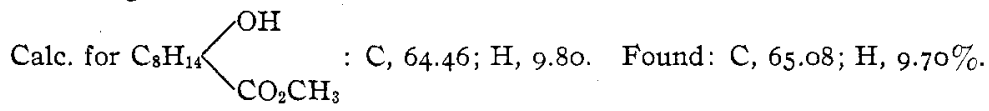

Methyl Ether of cis-Camphonolic Acid.-By slow crystallization from a mixture of ether and low boiling ligroin the acid separated in large, transparent, monoclinic prisms, the largest being two centimeters in length. The specific rotation of a solution in absolute alcohol containing 0.0455 g. $/$ cc. was $\alpha_{\mathrm{D}}^{28^{\circ}}=72.1^{\circ}$; m. p. $=87^{\circ}$ (corr.). A portion dissolved in alcohol and partially precipitated by careful addition of water gave the same melting point $\left(87-87.5^{\circ}\right)$. The substance was analyzed for carbon and hydrogen with the following results:

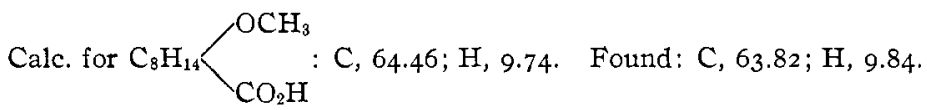

A rough Zeisel determination gave $15.5 \%\left(-\mathrm{OCH}_{3}\right)$ while the theory requires $16.6 \%$. Time was not taken to repeat this analysis since there was no doubt as to the nature of the compound.

The acid is volatile with steam and this volatility is increased considerably by distilling from a saturated salt solution. The melting point of the acid obtained in this way was $87-88^{\circ}$.

The melting point of a mixture of this acid and the ether acid (m. p. = $\left.84^{\circ}\right)^{1}$ obtained from isocampholactone was $45-50^{\circ}$. The mixture first became pasty and then melted gradually to a clear liquid. The two acids are, therefore, different.

The acid is not converted to the lactone by heating at $255^{\circ}$ for I5 minutes.

An attempt was made to prepared the hydriodide with a view of obtaining an unsaturated acid. Five-tenths of a gram of the acid was dissolved in carbon disulfide in which it is easily soluble. Gaseous hydrogen iodide was passed into the solution until the dark brown precipitate, which formed at first, no longer increased in amount. The product was extremely unstable and a melting point could not be obtained. After

${ }^{1}$ Noyes and Taveau, Am. Chem. J., 35, 381 (1906). 
standing overnight it was warmed on the steam bath with $5 \%$ sodium carbonate solution until a white crystalline substance remained, which was then extracted with ether. A few selected crystals melted at $\mathrm{I} 60-\mathrm{r} 6 \mathrm{r}^{\circ}$. This was shown to be identical with cis-camphonololactone by a mixed melting-point determination.

The silver salt was prepared by dissolving II.2979 g. of the acid in an equivalent $(20.4 \mathrm{cc}$.) of $2.98 \mathrm{~N}$ carbonate-free sodium hydroxide diluted with $25 \mathrm{cc}$. of water, and precipitated with a strong solution of silver nitrate containing Ir.5 g. $\mathrm{AgNO}_{3}$. The silver salt was filtered on a small Hirsch funnel and washed with cold water, alcohol, and finally with ether. The weight of the salt dried in vacuo over sulfuric acid was $17 \mathrm{~g}$. The salt dried at $100^{\circ}$ for a half hour gave the following analysis:

Salt, $0.1 \mathrm{IIg}, 0.1 \mathrm{I} 83 ; \mathrm{Ag}, 0.0412,0.0436$.

Calc. for $\mathrm{C}_{8} \mathrm{H}_{14}\left(\mathrm{OCH}_{8}\right) \mathrm{CO}_{2} \mathrm{Ag}$ : 36.82 . Found: $36.8 \mathrm{I}, 36.85$.

Ten grams of the above silver salt were covered with. anhydrous ether in a flassk sealed to an inner tube of a water condenser. To this was carefully added $8 \mathrm{~g}$. of methyl iodide dissolved in anhydrous ether. The contents of the flask was protected from the light and allowed to reflux gently on the steam bath for about six hours. The silver iodide and any unchanged silver salt were filtered off, the acid substances were removed by shaking with sodium carbonate solution, and the ether and excess of methyl iodide were distilled from the residual ester on the steam bath. The ester has a very pleasant odor and it distilled at II $6-1$ I $8^{\circ}$ (29-28 mm.). The temperature of the Woods metal bath was $135^{-140^{\circ}}$. For a solution in absolute alcohol containing $0.0903 \mathrm{~g} . / \mathrm{cc}$., $\alpha_{\mathrm{D}}^{20^{\circ}}=64.7^{\circ} ; \mathrm{d}_{4^{\circ}}^{25^{\circ}}=\mathrm{I} .004 \mathrm{I}$; $\mathrm{d}_{4}^{2 \circ^{\circ}}=1.0082$. The yield was $3 \mathrm{~g}$. The sodium carbonate solution upon acidification gave I g. of a crystalline product melting at $80-85^{\circ}$, evidently the impure ether acid.

The Unsaturated Acids. - The methyl ester of the unsaturated acids was saponified by refluxing 48 hours with I.5 mols of sodium hydroxide, using a solution of which $3 \mathrm{cc}$. were equivalent to $\mathrm{I} \mathrm{g}$. of $\mathrm{NaOH}$. The alcohol was distilled under diminished pressure in a comparatively large Claissen bulb. The residue was dissolved in water and, after filtering, the acid was taken up in ether from the acidified solution. The ester from the last nitrite decomposition gave more than $40 \mathrm{~g}$. of an acid having the following physical constants:

The boiling point was constant at $135^{\circ}\left(\mathrm{I} 4 \mathrm{~mm}\right.$.), $\mathrm{d}_{4}^{200^{\circ}}=\mathrm{I} .0132, \mathrm{~d}_{4}^{250^{\circ}}=\mathrm{I} .0088$, $\alpha_{\mathrm{D}}^{28^{\circ}}=105.2^{\circ}$. For a solution in absolute alcohol containing $0.1014 \mathrm{~g} . / \mathrm{cc}$. the rotation was $\alpha_{\mathrm{D}}^{20^{\circ}}=83.4^{\circ}, n_{\mathrm{C}}^{20^{\circ}}=1.47256, n_{\mathrm{D}}^{25^{\circ}}=1.47560, n_{\mathrm{F}}^{26^{\circ}}=1.48279, n_{\mathrm{G}}^{25}=1.48887$.

The unsaturated acid that would normally be expected should give camphoronic acid by oxidation. Five-tenths of a gram of the acid, 2 cc. of water, and $3 \mathrm{cc}$. of nitric acid ( $\mathrm{I} .4 \mathrm{O})$ were placed in a long, narrow test tube and the mixture was heated on the steam bath for a half hour. 
After purification a few crystals of an acid were obtained which melted indefinitely at about $150^{\circ}$, but as the yield was so very small this method of procedure was discontinued.

In the latter oxidation experiments potassium permanganate in alkaline solution was used. By this method better results were obtained by using a very large excess of permanganate. When slightly more than the theoretical amount was used the oxidation product remained as a viscous liquid. Many experiments were made under different conditions but the one that gave the best results is here described. In one case oxalic acid was isolated and identified by its melting point, titration, and analysis of the calcium salt for calcium.

Two and five-tenths grams of the acid were dissolved in $5.5 \mathrm{cc}$. of 2.98 $N$ sodium hydroxide solution. To this solution, cooled in ice, was added dropwise with constant shaking a solution of $10.5 \mathrm{~g} . \mathrm{KMnO}_{4}$ in $200 \mathrm{cc}$. of water. The permanganate color disappeared on standing and after 20 hours a solution of $5.2 \mathrm{~g} . \mathrm{KMnO}_{4}$ in $100 \mathrm{cc}$. of water was added. After standing five hours longer the contents of the flask were heated to the temperature of the steam bath with the addition of a little methyl alcohol to destroy the excess of permanganate. The manganese oxides were filtered hot with suction and the filtrate was treated with barium chloride solution. The white gelatinous precipitate was allowed to settle and filtered with suction. An excess of hydrochloric acid was added and the acid was evaporated in a vacuum desiccator over soda-lime and calcium chloride. The acid was taken up in alcohol and recrystallized from water, from which it separated in large transparent crystals upon slow evaporation in the vacuum desiccator. When heated rapidly it melted with decomposition at $155^{-1} 5^{\circ}$ (corr.). The yield was approximately $0.2 \mathrm{~g}$. No camphoronic acid was obtained. A solution in absolute alcohol containing $0.037 \mathrm{I} \mathrm{g} . / \mathrm{cc}$. showed no optical rotation.

$0.125 \mathrm{I}$ g. neutralized 23.1 cc. $0.0837 N \mathrm{KOH}$ solution. $0.0582 \mathrm{~g}$. from another preparation neutralized $17.9 \mathrm{cc}$. $0.05048 \mathrm{~N} \mathrm{KOH}$ solution. The calculated amounts for $\mathrm{C}_{8} \mathrm{H}_{11}\left(\mathrm{CO}_{2} \mathrm{H}\right)_{3}$ are, respectively, $23 . \mathrm{I} \mathrm{cc}$. and $\mathrm{I} 7.8 \mathrm{cc}$.

These data together with the fact that the acid decomposes at its melting point with the evolution of carbon dioxide establishes pretty clearly the fact that the acid is a derivative of malonic acid. This demonstrates that the unsaturated acid contains a $\Delta_{2}$ double union. Furthermore the unsaturated acid must retain the gem methyl in order to account for the optical inactivity.

Desiring to obtain the corresponding trimethyl glutaric acid the tribasic acid was heated for ten or fifteen minutes in a test tube placed in an oil bath at a temperature of $160-170^{\circ}$. The carbon dioxide was aspirated through calcium chloride and absorbed in a potassium hydroxide solution. $0.1242 \mathrm{~g}$. of the acid gave $0.0277 \mathrm{~g}$. carbon dioxide corresponding 
to $22.3 \% \mathrm{CO}_{2}$. Theory requires $22.6 \%$. The crystalline residue in the bottom of the tube was pressed out on a porous plate and the white powder was found to melt sharply at II I ${ }^{\circ}$ (corr.). It dissolved completely in Io\% sodium carbonate solution with the evolution of carbon dioxide. The structure of the new acid follows from the method of preparation.

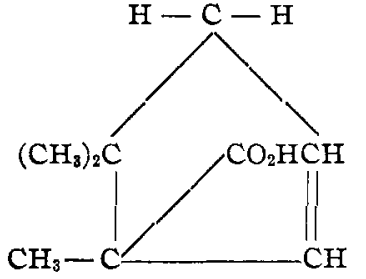

I,2,2-Trimethyl-I-carboxycyclopentene-4.

b. p. $=135^{\circ}$ ( $14 \mathrm{~mm}$.).

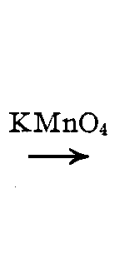

I,2,2-Trimethyl-1-carboxy
glutaric acid.

m. p. $=I 55^{-I 60^{\circ}}(\mathrm{de}-$ comp.).<smiles>CC(C(=O)O)C(C)(C)CC(=O)O</smiles>

I, 2,2-Trimethyl glutaric acid. m. p. $=I I^{\circ}$.

The filtrate from the barium salt of the unsaturated acid gave no precipitate when heated to boiling, showing that no camphoronic acid was present.

The amide prepared from the unsaturated acid in the manner used for lauronolic acid did not crystallize.

Hoping to obtain a crystalline derivative, Mulliken's method of preparing toluides was tried, but no toluide was obtained. The toluide obtained by treating the acid chloride with $p$-toluidine was a viscous liquid which would not crystallize.

The preparation of the $p$-nitro benzyl ester ${ }^{1}$ of the unsaturated acid was next tried. Seventy-one hundredths of a gram of the acid was dissolved in $1.56 \mathrm{cc}$. of $2.98 \mathrm{~N}$ sodium hydroxide with the addition of 3.44 cc. of water. To this was added r.o g. of p-nitrobenzyl bromide dissolved in Io cc. of $95 \%$ alcohol. The mixture was heated on the steam bath under a reflux for 40 minutes. 'Turbidity appeared after about five minutes' heating. To keep the ester in solution about $5 \mathrm{cc}$. I : 2 solution of water in alcohol was added during the first 15 or 20 minutes. The reaction mixture was cooled quickly by shaking the flask under cold running water. A mobile oil precipitated. This is, of course, not satisfactory for purposes of identification.

A drop of the acid was placed on each of 48 small watch glasses in a desiccator evacuated to $20 \mathrm{~mm}$. Nitrogen dioxide, obtained by heating lead nitrate was passed in until atmospheric pressure was almost restored. The acid turned green but no crystalline material separated then or after standing out of doors overnight. The material was dissolved in ether and the unchanged acid was extracted with ro $\mathrm{cc}$. of a sodium carbonate

1 This Journal, 39, 27 (I9I7). 
solution. The residue from the evaporation of the ether partially crystallized and after pressing out on porous porcelain the melting point was $144^{-1} 5^{\circ}$. Recrystallization from a mixture of ether and petroleum ether gave transparent needles melting at $17 \mathrm{I}-173^{\circ}$. The rotation for a solution in absolute alcohol containing $0.0088 \mathrm{~g} . / \mathrm{cc}$. was $\alpha_{\mathrm{D}}^{25^{\circ}}=-8^{\circ}$. Schryver ${ }^{1}$ gives for nitrocampholactone, m. p. $=170^{\circ}$. Noyes and Tippet $^{2}$ give, m. p. $=17 \mathrm{I}^{\circ}$.

This unsaturated acid, if it is a pure substance, should give a dihydro acid which would be different from dihydrolauronolic acid. About $30 \mathrm{~g}$. of the unsaturated acid were wasted in efforts to obtain such a dihydro acid. Reduction experiments were carried out with zinc dust and absolute alcohol in the manner used for lauronolic acid and also with colloidal palladium. Two representative experiments for the reduction with zinc dust are here given.

Six grams of the unsaturated acid were dissolved in carbon disulfide in a U-tube surrounded by a freezing mixture of hydrochloric acid and ice. Gaşeous hydrogen iodide was passed slowly through the solution for an afternoon. The hydriodide did not precipitate. The carbon disulfide was evaporated in a current of dry air and finally under diminished pressure keeping the mixture cold. The residue was dissolved in absolute alcohol and an excess of zinc dust was added. About I cc. of fuming hydriodic acid was added after a few minutes, and gaseous hydrogen iodide was passed into the solution. Finally some concentrated hydrochloric acid was added. When all of the zinc had disappeared the mixture was diluted with water and extracted with ether. The ether extract was shaken with sodium carbonate solution to separate the lactone. The sodium carbonate solution reduced instantly a strong permanganate solution which was added until the pink color remained. The manganese oxides were reduced by passing in a stream of sulfur dioxide, keeping cold. Some sulfuric acid was added and the product was distilled with steam.

The experiment was carried out in another way by passing in the hydrogen iodide rapidly for a short time. The carbon disulfide residue was a viscous liquid. An emulsion of zinc dust in absolute alcohol was added at once with shaking. One or $2 \mathrm{cc}$. of fuming hydriodic acid were added and then gradually with shaking and cooling a few cc. of hydrochloric acid. After about fifteen minutes the insoluble material was filtered off on a small Hirsch funnel and washed with a little petroleum ether. In this way no bothersome precipitate of inorganic material resilted when this solution was shaken with sodium carbonate solution. Large transparent plates remained after evaporation of the ether. The weight was 0.7 g. m. p. $=45^{-} 5^{\circ}$. The dihydro acid was separated as before.

1 J. Chem. Soc., 73, 550 (1898).

2 Thesis, University of Illinois, I9I5. 
The supposed dihydro acid from $24 \mathrm{~g}$. of the unsaturated acid weighed $2.4 \mathrm{~g}$. and distilled at $100-130^{\circ}$ ( $15 \mathrm{~mm}$.). This product reduced permanganate instantly and consisted chiefly of the unsaturated acid. The portion which did not dissolve in sodium carbonate weighed one gram and distilled over a range of temperature at about $90^{\circ}$ ( $15 \mathrm{~mm}$.). When the above lactone was recrystallized from petroleum ether it melted sharply at $49 \cdot 5-50.5^{\circ}$. The rotation for a solution in absolute alcohol containing $0.05926 \mathrm{~g}$. $/ \mathrm{cc}$. was $\alpha_{\mathrm{D}}^{24^{\circ}}=-26.5^{\circ}$. Noyes ${ }^{1}$ gives for the lactone obtained from $\gamma$-lauronolic acid, m. p.. $=48-49^{\circ}$. Noyes and Burke ${ }^{2}$ give for the lactone obtained from lauronolic acid, m. p. $=50^{\circ} ; \alpha_{\mathrm{D}}^{22^{\circ}}=-21.7^{\circ}$. We have prepared the lactone from lauronolic acid and have found it to be identical with our lactone by a determination of the mixed melting point.

The lactone was converted to the hydroxy acid, which was obtained in the form of white crystals melting at $143^{-1} 45^{\circ}$ (uncorr.). The rotation for a solution in absolute alcohol containing $0.0379 \mathrm{~g}$. $/ \mathrm{cc}$. was $\alpha_{\mathrm{D}}^{24.5^{\circ}}=6^{\circ}$. Tiemann ${ }^{3}$ gives, m. p. $=145^{\circ}$. Noyes and Burke give, m. p. $=143^{\circ}$; $\alpha_{\mathrm{D}}^{27^{\circ}}=\mathrm{I} 6^{\circ}$.

0.1139 g. neutralized I3.I 6 cc. of $0.05048 \mathrm{~N} \mathrm{KOH}$.

Calc. for $\mathrm{C}_{8} \mathrm{H}_{14}-\mathrm{CO}_{2} \mathrm{H}$ : $13.1 \mathrm{I} \mathrm{cc}$.

An attempt was made to oxidize it to a ketonic acid but only the lactone and a very small amount of unchanged acid resulted.

The same lactone was obtained from the unsaturated acid by heating it with dilute acids. The following experiments are illustrative of the results obtained:

One gram of the unsaturated acid was placed in a loosely stoppered test tube with ro cc. of hydrochloric acid ( $(\mathrm{i}: \mathrm{r}$ ) and allowed to stand at approximately $50^{\circ}$ for about 70 hours. The material, which darkened considerably, was subjected to steam distillation and the unchanged acid (o.5 g.) was separated with sodium carbonate. The liquid lactone after standing out of doors at about the freezing temperature partially crystallized and after pressing out on cold porous plate the crude lactone melted at $45^{-}-48^{\circ}$.

By shaking I $\mathrm{g}$. of the acid at the temperature of the steam bath for twenty minutes with sulfuric acid $(I: 2), 0.2 \mathrm{~g}$. of the lactone and 0.7 g. of the unchanged acid were obtained. Slightly better results were obtained by the use of sulfuric acid ( $I: r$ ), although there was more charring.

The colloidal palladium used in other reduction experiments was obtained by shaking a solution of gum arabic and palladous chloride in an

${ }_{1}$ Am. Chem. J., I7, 434 (1895).

2 This Journal, 34, I82 (I9I2).

s Ber., 33, 2946 (I900). 
atmosphere of hydrogen. Five grams ${ }^{1}$ of the acid were dissolved in a slight excess of sodium hydroxide and the solution was saturated with carbon dioxide. The mixture was shaken intermittently at a temperature of $100^{\circ}$ for sixteen hours by means of a mechanical shaking apparatus. No dihydro acid was obtained, although the palladium remained colloidal for the entire time.

The acid gives a bromolactone by the action of bromine. Two representative experiments are here given.

Two grams of the acid were dissolved in chloroform in a bulb. To this was added with shaking and cooling a solution of bromine in chloroform until the bromine color remained. Dense fumes of hydrobromic acid were evolved. After evaporating the chloroform in a stream of dry air the semi-crystalline residue was pressed out on porous porcelain to absorb any liquid material. The crystalline residue was then distilled with steam. It melted rather indefinitely at about $183^{\circ}$. The weight was $2 \mathrm{~g}$. By dissolving in methyl alcohol and precipitating with an equal volume of water a product was obtained which melted at $191-192^{\circ}$, and which weighed I.4 $\mathrm{g}$.

In another experiment in which the same amount of the unsaturated acid was used, the chloroform residue was dissolved in ether. The ether solution was shaken with sodium carbonate solution to remove a little dibromo acid, which was too small in amount to investigate. The ether residue weighed $2 \mathrm{~g}$. and melted below $160^{\circ}$ over a wide range. It was crystallized from petroleum ether in which it is not so soluble as in other organic solvents. The melting point was then $186-187^{\circ}$. It was then crystallized repeatedly from hot ligroin (b. p. $=70^{\circ}$ ) with the following results:

I. m. p. $=I 87-I 88^{\circ} ; 2$ II. m. p. $=190-I 9 I^{\circ}$; III. m. p. $=I 9 I-192^{\circ} ;$ IV.m. p. $=$ $192-193^{\circ}$ (weight $=0.5 \mathrm{~g}$. ).

$0.1395 \mathrm{~g}$. of the substance by the Carius method gave o.1132 g. AgBr corresponding to $34.53 \%$ bromine. Calc. for $\mathrm{C}_{8} \mathrm{H}_{13} \frac{{ }_{0}^{\mathrm{Br}}}{\mathrm{C}}=\mathrm{O}: 34.30 \%$.

The rotation of a sample of the lactone which had been distilled with steam but had not been recrystallized was for a solution in absolute alcohol containing $0.0937 \mathrm{~g} . / \mathrm{cc}$., $\alpha_{D}^{24^{\circ}}=48^{\circ}$. This determination has not yet been repeated with the purest lactone obtained. The bromo lactone from lauronolic acid has been prepared and the two are identical as shown by the mixed melting point.

The bromo lactone was saponified. The viscous residue from the ether extract of the acid was dissolved in $50 \%$ alcohol and the resulting solution

3 Ber., 41, 2275 (1908); Ann., 388, 56 (1912).

2 Anschütz thermometer. 
was concentrated in vacuo over calcium chloride. Some oily drops separated at first but on complete evaporation a white crystalline residue was obtained, which melted at $135-150^{\circ}$. A white precipitate from an ether solution resulted with petroleum ether, which melted sharply at I $72-173^{\circ}$ (uncorr.). The rotation for a solution in absolute alcohol containing $0.0077 \mathrm{~g} \cdot / \mathrm{cc}$. was $\alpha_{\mathrm{D}}^{23^{\circ}}=6^{\circ}$.

0.0290 g. required $2.9 \mathrm{cc}$. of $0.04979 \mathrm{~N} \mathrm{KOH}$ for neutralization.

$(\mathrm{OH})_{2}$

$\mathrm{OH}$

Calc. for $\mathrm{C}_{8} \mathrm{H}_{13}-\mathrm{CO}_{2} \mathrm{H}: 3.0$ cc. Calc. for $\mathrm{C}_{8} \mathrm{H}_{14}-\mathrm{CO}_{2} \mathrm{H}: 3.4 \mathrm{cc}$.

Five grams of the unsaturated acid were distilled from powdered anhydrous zinc chloride to convert it to the hydrocarbon. The distillate was poured back into the same bulb and distilled again. The distillate was washed with sodium hydroxide solution, dried with calcium chloride and then distilled at atmospheric pressure. The third fractionation gave I.4 $\mathrm{g}$. of a product boiling at II $8-120^{\circ}$. The specific gravity was $\mathrm{d}_{4^{\circ}}^{25^{\circ}}=$ $0.7871 ; \mathrm{d}_{4}^{20^{\circ}}=0.7923$. The rotation of the liquid hydrocarbon was $\alpha_{\mathrm{D}}^{23^{\circ}}=0.7^{\circ}$; for a solution in absolute alcohol containing $0.0308 \mathrm{~g} . / \mathrm{cc}$. it was $\alpha_{\mathrm{D}}^{25^{\circ}}=-\mathrm{I} . \mathrm{I}^{\circ} ; n_{\mathrm{D}}^{25^{\circ}}=\mathrm{I} .444^{26} ; n_{\mathrm{C}}^{25^{\circ}}=\mathrm{I} .44 \mathrm{I} 2 \mathrm{I} ; n_{\mathrm{F}}^{25^{\circ}}=\mathrm{I} .45099$; $n_{\mathrm{G}^{\prime}}^{25^{\circ}}=\mathrm{I} .45695$.

Eykman $^{1}$ gives for laurolene, b. p. $=119^{-120^{\circ}}(744 \mathrm{~mm}.) ; \mathrm{d}^{17.3^{\circ}}=$ 0.7992. Noyes and Burke ${ }^{2}$ give b. p. $=120-12 \mathrm{I}^{\circ} ; \alpha_{\mathrm{D}}^{300^{\circ}}=-5.36^{\circ}$. Noyes and Derick ${ }^{3}$ found for the laevo laurolene obtained from the decomposition of the nitroso derivative from aminocamphonanic anhydride, $\alpha_{\mathrm{D}}^{20^{\circ}}=-\mathrm{I} 4.5^{\circ} ; \mathrm{d}_{4^{\circ}}^{15^{\circ}}=0.8043$.

As a further means of identification the preparation of the calcium salt was tried. The acid was heated on the steam bath with water and finely powdered calcium carbonate. The solution of the salt was filtered and concentrated on the steam bath. The salt represented in the first four analyses was prepared by evaporation in an open dish. In all other cases the evaporation was carried out in an Erlenmeyer flask. In this way the crystals separated throughout the liquid instead of separating at the surface. In the latter case the crystals were transparent prisms with hemihedral facets. In one case two kinds of crystals were obtained, one consisting of transparent plates and the other of rosets of radiating fibers. According to the analyses they contained three and two molecules of water, respectively. The acid recovered from the rosets gave a rotation of $\alpha_{\mathrm{D}}^{29^{\circ}}=83.4^{\circ}$ for a solution in absolute alcohol containing $0.0156 \mathrm{~g} . / \mathrm{cc}$. The weight of the rosets was nearly four times that of the plates. Two samples of the salt prepared from the acid obtained from one of the later nitrite decompositions after drying at IIO-II $5^{\circ}$ gave an acid for which

${ }^{1}$ Book by J. H. Hoving referred to in this article.

${ }^{2}$ This Journal, 34, I80 (I912).

${ }^{3} \mathrm{Ibid} .$, 32, I06I (I910). 
$\alpha_{\mathrm{D}}^{30^{\circ}}=97^{\circ}$ (0.03I34 g./cc.). The recovered acid seemed to be more viscous than before but it did not darken very much. It is interesting to note that the purest acid which has been obtained from the nitrite decomposition gives a rotation which is identical with that obtained from the rosets.

\begin{tabular}{|c|c|c|c|c|c|c|}
\hline Sample. & Time. & Temperature. & $\begin{array}{l}\text { TABLE IIY. } \\
\text { Decrease } \\
\text { in weight. }\end{array}$ & $\mathrm{H}_{2} \mathrm{O}$. & $\begin{array}{l}\text { Weight } \\
\text { of CaSO }\end{array}$ & $\mathrm{Ca}$. \\
\hline $\begin{array}{l}0.1255 \mathrm{~g} . \\
0.1374 \\
\text { Plates }\end{array}$ & $\cdots$ & $\begin{array}{l}120^{\circ} \\
120^{\circ}\end{array}$ & $\begin{array}{l}0.0166 \mathrm{~g} . \\
0.0202\end{array}$ & $\begin{array}{l}13.23 \% \\
13.90\end{array}$ & $\begin{array}{l}0.044^{8} \mathrm{~g} . \\
0.0490\end{array}$ & $\begin{array}{l}10.51 \% \\
10.50^{1}\end{array}$ \\
\hline $\begin{array}{l}\text { O. I I } 24 \\
\text { Rosets }\end{array}$ & $\ldots$ & $\operatorname{IIO}-\operatorname{II} 5^{\circ}$ & 0.015 I & $x_{3} \cdot 43$ & 0.0390 & $9.99^{1}$ \\
\hline $0.145^{2}$ & 2.5 hours & $105^{-110^{\circ}}$ & 0.0138 & 9.5 & 0.0528 & I0. $70^{1}$ \\
\hline 0.1359 & 2.5 hours & $105^{-1} 10^{\circ}$ & 0.0143 & 10.52 & 0.0501 & $10.85^{1}$ \\
\hline 0.2045 & 2 hours & IIO-II $5^{\circ}$ & 0.0244 & II . 93 & 0.0721 & $10.3^{1}$ \\
\hline 0.1225 & $\cdots$ & $\ldots$ & . & $\ldots$ & 0.0446 & $10.70^{1}$ \\
\hline 0.1504 & 3 hours & $100-105^{\circ}$ & 0.0153 & 10. I 7 & 0.0535 & 10. $47^{1}$ \\
\hline o. 1593 & hours & $100-105^{\circ}$ & 0.0163 & 10.23 & 0.0564 & $10.42^{1}$ \\
\hline 0.3055 & hours & $105^{-108^{\circ}}$ & $0.039 I$ & 12.79 & 0.1097 & IO. $57^{1}$ \\
\hline 0.2680 & I hours & $105^{-108^{\circ}}$ & 0.0307 & $\begin{array}{l}\text { I } 1.45 \text {. } \\
\text { Avera }\end{array}$ & $\begin{array}{l}0.0947 \\
\mathrm{Ca}=\mathrm{I}\end{array}$ & $10.40^{1}$ \\
\hline
\end{tabular}

The analyses are not satisfactory, especially for water of crystallization. Constant weight was never obtained upon heating the beautifully crystalline salt even at the lowest temperatures, and a pleasant odor was always developed even when the salt remained perfectly white. The salt used in the analysis was dried between layers of hardened filter paper and immediately pulverized in an agate mortar. It was neither efflorescent or deliquescent. The analyses for calcium indicate that the salt contains 2 molecules of water and is probably mixed with a little of the monohydrated salt. It appeared to be more soluble in cold than in hot water.

The above experiments force one to the conclusion that the acid is almost entirely lauronolic acid, containing a small amount of the $\Delta^{2}$ acid, from which no satisfactory method of separation has been found, and none of the unsaturated acid that would normally be expected.

cis-Camphonolic Acid.-An earlier preparation of this acid melting at $195.5^{\circ}$ (corr.), gave a rotation of $\alpha_{\mathrm{D}}^{27^{\circ}}=32.1^{\circ}$ for a solution in absolute alcohol containing $0.09 \mathrm{I} 2 \mathrm{~g} . / \mathrm{cc}$. In the later preparations we obtained a purer acid melting at $20 \mathrm{O}-2 \mathrm{O} 2^{\circ}$, but the rotation of this has not yet been taken.

Five-tenths of a gram of the acid melting at $195.5^{\circ}$ was converted to cis-camphonololactone by heating in a bath of paraffin at $255^{\circ}$ for ten minutes. M. p., $16 \mathrm{I}-162^{\circ}$ (corr.). The rotation for a solution in absolute alcohol containing $0.0647 \mathrm{~g} . / \mathrm{cc}$. was $\alpha_{\mathrm{D}}^{27^{\circ}}=-\mathrm{I} 6.8^{\circ}$.

I These values were averaged. 
The acid was further identified by oxidation to camphononic acid. M. p. $=228^{\circ}$ (corr.). The rotation for a solution in absolute alcohol containing $0.0230 \mathrm{~g} . / \mathrm{cc}$. was $\alpha_{\mathrm{D}}^{30^{\circ}}=-3.9^{\circ}$.

cis-Camphonolic acid should give $d$-camphoric acid through the following series of reactions:
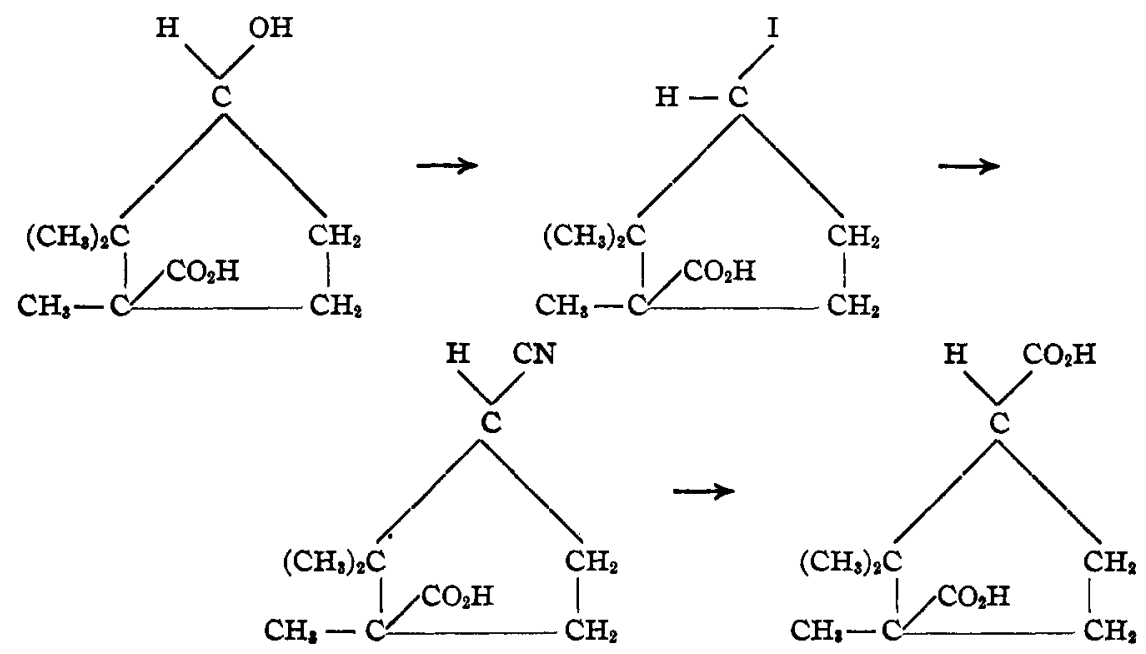

After it became apparent that the free acid could not be used for this purpose the methyl ester was tried. Pure cis-camphonolic acid (5.0483 g.) was dissolved in $9.84 \mathrm{cc}$. of $2.98 \mathrm{~N}$ carbonate-free sodium hydroxide. To this was added a solution of $5.5 \mathrm{~g}$. of silver nitrate dissolved in ro cc. of water. The silver salt was filtered on a small Hirsch funnel and washed with water, alcohol and ether. Analysis gave the following results:

Substance $0.1678,0.1499 ; \mathrm{Ag}, 0.065 \mathrm{r}, 0.0579$. Found: $38.58,38.62 \%$.

Calc. for $\mathrm{C}_{8} \mathrm{H}_{34}-\mathrm{CO}_{2} \mathrm{Ag}: 38.67 \%$.

Eleven and two-tenths grams of the silver salt were refluxed with an excess of methyl iodide in absolute ether overnight. The silver salts were filtered and the ether solution was extracted with ro\% sodium carbonate solution to remove the acid substances. The weight of the ester which nearly all distilled at $130^{-1} 34^{\circ}$ ( $\mathrm{I} g \mathrm{~mm}$.) was $3.2 \mathrm{~g}$. The substance gave the following constants:

$\mathrm{d}_{4}^{20^{\circ}}=1.0535 ; \mathrm{d}_{4}^{25^{\circ}}=1.0489$. For the liquid ester $\alpha_{\mathrm{D}}^{26.5^{\circ}}=32.9^{\circ}$. For a solution in absolute alcohol containing $0.09916 \mathrm{~g} . / \mathrm{cc} \cdot \alpha_{\mathrm{D}}^{25.5^{\circ}}=$ $34.0^{\circ}$.

Attempts to obtain a stable halogen compound of the ester also resulted in failure, the lactone being formed as before. To the crystalline iodide, which melts below room temperature, was added immediately $25 \mathrm{cc}$. of 
a saturated solution of potassium cyanide in methyl alcohol. The alcohol was distilled under diminished pressure. The residue was taken up in water and ether. A viscous oil was left from the evaporation of the ether which did not give ammonia when dropped on hot soda-lime, or Prussian blue after fusion with sodium.

$3.2 \mathrm{~g}$. of the acid portion obtained in the preparation of the methyl ester were dissolved in a small portion of benzene with warming and then treated with two volumes of petroleum ether to precipitate the cis-camphonolic acid ( 0.8 g.). The ether acid, $\mathrm{C}_{8} \mathrm{H}_{14} \succ_{\mathrm{OCH}_{3}}^{\mathrm{CO}_{2} \mathrm{H}}$ constituted the main portion of the soluble residue from which it was separated by fractional precipitation. It was shown to be identical with the ether acid obtained in the nitrite decomposition by a determination of the mixed melting point. An attempt to prepare the methyl ether of cis-camphonolic ester by the action of methyl iodide on the sodium salt resulted merely in the saponification of the ester. It is hoped to repeat this more carefully.

The formation of the ether acid here is similar to the formation of the ether acid of the hydroxy acid corresponding to isocampholactone observed by Noyes and Taveau. ${ }^{1}$ We are not aware that any other account of a similar reaction between a silver salt of a hydroxy acid and methyl iodide has been reported.

The Other Hydroxy Acids.- - The acid obtained from the saponification of the ester boiling at II2-II4 (I8 mm.) distilled mostly at I8O-I82 ( $18 \mathrm{~mm}$.). Five and five-tenths grams of the ester yielded $4 \mathrm{~g}$. of the acid, which had a slightly greenish tint. The silver salt precipitated from a solution of the calcium salt and dried in a water oven gave the following analysis:

0.1063 g. gave 0.0413 g. Ag or $38.85 \%$. 0.1187 g. gave 0.0462 g. Ag or $38.92 \%$. Calc. for $\mathrm{C}_{8} \mathrm{H}_{14}-\mathrm{CO}_{2} \mathrm{Ag}: 38.67 \%$.

The solution of the calcium salt was concentrated to a small volume on the steam bath and then finally in a vacuum desiccator over calcium chloride. A white crystalline salt separated which was filtered off on a small Hirsch funnel. The mother liquors upon complete evaporation left a substance which looked like glue and did not crystallize. The analysis of the crystalline salt dried at $100^{\circ}$ was as follows:

$0.1923 \mathrm{~g}$. heated at $155-160^{\circ}$ for one hour gave $0.0097 \mathrm{~g} . \mathrm{H}_{2} \mathrm{O}, 0.0266 \mathrm{~g} . \mathrm{CaO}$ and 0.0659 g. $\mathrm{CaSO}_{4}$.

$0.1947 \mathrm{~g}$. gave $0.0097 \mathrm{~g} . \mathrm{H}_{2} \mathrm{O}, 0.0269 \mathrm{~g} . \mathrm{CaO}$ and $0.0657 \mathrm{~g}$. $\mathrm{CaSO}_{4}$.

${ }^{1}$ Am. Chem. J., 35, 381 (1906). 


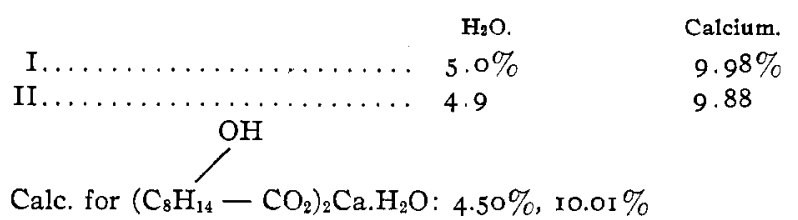

In the next saponification experiment, $7 \mathrm{~g}$. of the acid boiling mostly at $180-182^{\circ}(18 \mathrm{~mm}$.) were obtained. While preparations were being made to convert it into the calcium salt crystals began to appear in the receiving bulb. A small portion of the material was taken out on the point of a glass rod and allowed to stand on porous porcelain to absorb the oily material. M. p. $=80-95^{\circ}$. The crystals dissolved immediately in $10 \%$ sodium carbonate solution with the evolution of carbon dioxide. The resulting solution was stable toward permanganate. To the entire amount of the acid in the bulb a little petroleum ether was added and the mixture was cooled in a freezing mixture. The white silky crystals were filtered off on a Hirsch funnel. M. p. $=80-95^{\circ}$. The material ( $\mathrm{r} .5 \mathrm{~g}$.) was then dissolved in a little hot benzene. An equal volume of ligroin was added and the solution was concentrated to a small volume. On cooling the whole solidified to a white solid mass of silky needles which melted at $95-100^{\circ}$. When crystallized once more one gram of the acid melting at $100-102^{\circ}$ was obtained. The best way to purify the acid is to crystallize the sodium salt.

0.1094 g. required $12.78 \mathrm{cc}$. of $0.04979 \mathrm{~N} \mathrm{KOH}$ for neutralization.

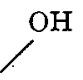

Calc. for $\mathrm{C}_{8} \mathrm{H}_{14}-\mathrm{CO}_{2} \mathrm{H}: \quad 12.76 \mathrm{cc}$.

The rotation for a solution in absolute alcohol containing $0.07016 \mathrm{~g} . / \mathrm{cc}$. was $\alpha_{\mathrm{D}}^{26^{\circ}}=35.6^{\circ}$.

Five-tenths of a gram of the acid was oxidized with potassium dichromate and sulfuric acid in the manner used for cis-camphonolic acid in an apparatus for detecting the evolution of carbon dioxide. After standing 54 hours there was no appreciable darkening of the dichromate and no carbon dioxide was evolved. The crude hydroxy acid which was recovered gave a rotation of $\alpha_{\mathbb{D}}=34^{\circ}$.

As a preliminary experiment $0.5 \mathrm{~g}$. of the residual liquid hydroxy acid was also oxidized in the above manner. The dichromate began to darken immediately, evidence of carbon dioxide being obtained in 3 hours. After standing 8 hours the mixture was diluted with 2 cc. of dilute sulfuric acid (I : I) and allowed to stand 40 hours with occasional shaking. The residue from the ether extract was distilled with steam. No oil separated in the distillate but it gave a decided test for a ketone with phenyl hydrazine. The precipitate was noncrystalline and too small in amount to investigate. The phenylhydrazone of the nonvolatile portion precipitated as a gummy 
substance. The rotation of this hydroxy acid was $\alpha_{\mathrm{D}}^{23.5^{\circ}}=\mathrm{Ir} .5^{\circ}$ for a solution in absolute alcohol containing $0.09824 \mathrm{~g} . / \mathrm{cc}$.

$0.104 \mathrm{I} \mathrm{g}$. of the silver salt gave $0.0400 \mathrm{~g}$. of silver corresponding to $38.6 \mathrm{I} \%$. $\mathrm{OH}$

$\mathrm{C}_{8} \mathrm{H}_{14}-\mathrm{CO}_{2} \mathrm{Ag}$ requires $38.67 \%$.

Five-tenths of a gram of the crystalline hydroxy acid was suspended in carbon disulfide and kept cold in a freezing mixture. Gaseous hydrogen iodide was passed in until solution resulted. The yellow crystals left on evaporation of the carbon disulfide melted fairly sharply at $85^{-8} 87^{\circ}$ although there was some decomposition. The product decomposed on standing. The carbon disulfide solution of the iodide after partial evaporation was shaken at once with sodium hydroxide solution. Merely sulfur remained in the carbon disulfide layer, no lactone being formed. The acid instantly reduced permanganate. The rotation for a solution in absolute alcohol containing $0.04104 \mathrm{~g}$. $/ \mathrm{cc}$. was $\alpha_{\mathrm{D}}^{25^{\circ}}=\mathrm{I}_{4} 2^{\circ}$. This is in as good agreement with lauronolic acid as could be expected, since the rotation of this acid varies within comparatively wide limits. The bromolactone melted at $193^{-194^{\circ}}$ and was shown to be identical with the bromolactone obtained from lauronolic acid by a determination of the mixed melting point.

The liquid hydroxy acid from which the above crystalline hydroxy acid was separated was treated with gaseous hydrogen iodide in the same manner to obtain the unsaturated acid. A lactone was also obtained which melted at $47-48^{\circ}$. This was shown to be identical with campholactone by a determination of the mixed melting point. The rotation of the acid for a solution in absolute alcohol containing $0.03312 \mathrm{~g} . / \mathrm{cc}$. was $\alpha_{\mathrm{D}}^{26^{\circ}}=88.4^{\circ}$. The bromolactone after steam distillation melted at

Concentrated Ether Solution

\begin{tabular}{|c|c|c|c|}
\hline \multicolumn{4}{|c|}{$\begin{array}{l}\text { Concentrated Ether Solution } \\
\qquad \begin{array}{l}\text { Petroleum } \\
\text { Ether }\end{array}\end{array}$} \\
\hline \multirow{5}{*}{$\begin{array}{c}\text { Insoluble } \\
\text { Cis-camphonolic } \\
\text { Acid }\end{array}$} & & \multicolumn{2}{|c|}{ Soluble } \\
\hline & \multirow{4}{*}{$\begin{array}{c}\text { Insoluble } \\
\text { Calcium Salt of Acid } \\
\text { m. p. = IOI-IO2 } \\
\downarrow \text { Sodium Salt } \\
\text { Sodium salt crystal- } \\
\text { lizes from hot con- } \\
\text { centrated solution in } \\
\text { long, white needles }\end{array}$} & \multicolumn{2}{|c|}{ 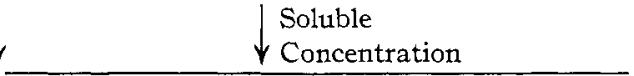 } \\
\hline & & \multirow{2}{*}{$\begin{array}{l}\text { Crystalline } \\
\text { Calcium salts of acid, } \\
\text { m. p. }=\text { IOI-IO2 }{ }^{\circ} \text { and } \\
\text { cis-camphonolic acid } \\
\downarrow \text { Sodium Salt }\end{array}$} & \multirow{3}{*}{$\begin{array}{l}\text { Non-crystalline } \\
\text { Calcium salt of liquid } \\
\text { hydroxy acid as a } \\
\text { syrupy liquid }\end{array}$} \\
\hline & & & \\
\hline & & 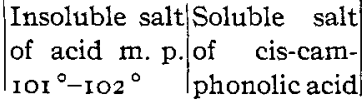 & \\
\hline
\end{tabular}


189-19I ${ }^{\circ}$ and was shown to be identical with the bromolactone from the unsaturated acid obtained in the nitrite decomposition.

The method finally adopted in the separation of cis-camphonolic, the crystalline and liquid hydroxy acids from the intermediate fractions is given diagrammatically on page 2713

Decomposition of the Methyl Ester of Camphonanic Acid.-The formation of the methyl ether of cis-camphonolic acid in the decomposition of methyl isoaminocamphonate was so unexpected that the methyl esters of two other amino acids of this series were decomposed in order to see if there would be a similar result. The method used in the preparation of the methyl ester of aminocamphonanic acid was in general that used in the preparation of the ester of isoaminocamphonanic acid. However, very poor yields were obtained in the hypobromite reaction and the initial preparation of the amino acid ${ }^{1}$ and subsequent esterification is to be recommended.

The dimethyl $d$-camphorate boiled at $155^{\circ}$ (25 mm.) or $144^{\circ}$ ( $15 \mathrm{~mm}$.) and gave a rotation of $\alpha_{\mathrm{D}}^{29^{\circ}}=47.5^{\circ}$. For a solution in absolute alcohol containing $0.1036 \mathrm{~g} . / \mathrm{cc} ; \quad \alpha_{\mathrm{D}}^{31^{\circ}}=45.8^{\circ} ; \mathrm{d}_{4}^{20^{\circ}}=\mathrm{r} .0768 ; \mathrm{d}_{4}^{25^{\circ}}=1.0727$. The $\beta$-methyl, $\alpha$ - $d$-camphoramidate melted at $154-155^{\circ}$. The rotation for a solution in absolute alcohol containing $0.0974 \mathrm{~g} . / \mathrm{cc}$. was $\alpha_{\mathrm{D}}^{28^{\circ}}=23.1^{\circ}$. Three hundred and seventy grams of the amide ester gave $84 \mathrm{~g}$. of the hydrochloride of the amine ester. This melted at $237^{\circ}$ and the rotation for a solution in absolute alcohol containing $0.1073 \mathrm{~g}$. $/ \mathrm{cc}$. was $\alpha_{\mathrm{D}}^{30^{\circ}}=26.2^{\circ}$. Seventy-nine $g$. of the hydrochloride were decomposed with sodium nitrite in slightly acid solution. No ether acid was obtained upon extracting the products with a sodium carbonate solution. The first distillation of the decomposition products gave the following fractions:

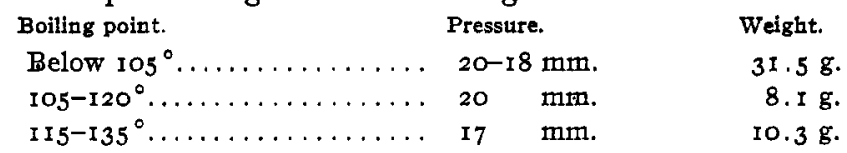

After fractionating twice more $18.2 \mathrm{~g}$. of an ester boiling at $78-85^{\circ}$ (15 mm.) was obtained. The rotation for a solution in absolute alcohol containing $0.0925 \mathrm{~g} . / \mathrm{cc}$. was $\alpha_{\mathrm{D}}^{28.5^{\circ}}=73.8^{\circ}$. From this ester 14.1 $\mathrm{g}$. of an unsaturated acid boiling at $125^{-1} 30^{\circ}$ (ro mm.) was obtained, which gave a rotation of $\alpha_{\mathrm{D}}^{28.5^{\circ}}=108 . \mathrm{I}^{\circ} ; \mathrm{d}_{4}^{20^{\circ}}=$ ro.090; $\mathrm{d}_{4}^{20^{\circ}}=$ I.0r30. For a solution in absolute alcohol containing $0.096 \mathrm{I} 4 \mathrm{~g}$./cc. the rotation was $\alpha_{\mathrm{D}}^{27.5^{\circ}}=85.3^{\circ}$. It is the intention of the junior author to study these products further.

Decomposition of Methyl Aminodihydrocampholytate.-This ester was prepared by esterifying the crude amino acid from $\beta$ - $d$-camphoramidic acid. Seventy-nine and six-tenths grams of this acid gave $64 \mathrm{~g}$. of the ${ }^{1}$ Am. Chem. J., 32, 287 (1904). 
hydrochloride. This melted sharply to a clear liquid at $I 86.5^{\circ}$. The rotation for a solution in absolute alcohol containing $0.04684 \mathrm{~g}$./cc. was $\alpha_{D}^{26.3^{\circ}}=48.8^{\circ}$. No ether acid was obtained. The esters upon fractionating a second time gave the following fractions:

\begin{tabular}{|c|c|c|}
\hline Boiling poin & Pressure. & Weight. \\
\hline $80-90^{\circ}$. & $15 \mathrm{~mm}$. & $8.8 \mathrm{~g}$. \\
\hline $90-115^{\circ}$. & . & I. 3 \\
\hline $\operatorname{II} 5^{-125^{\circ}}$. & I5 & 1.3 \\
\hline II $123^{\circ}$. & IO & $7 \cdot 3$ \\
\hline
\end{tabular}

The Ether Acid from Isocampholactone.-Noyes and Taveau ${ }^{1}$ obtained an ether acid which melted at $84^{\circ}$ by treating the silver salt of the hydroxy acid derived from isocampholactone with methyl iodide. We have repeated this preparation in order to see if it were identical with the methyl ether of cis-camphonolic acid, which we have obtained. Sixteen and five-tenths grams of the silver salt were warmed gently under a reflux for seven hours with an excess of methyl iodide in ether. The fraction soluble in sodium carbonate solution weighed $0.4 \mathrm{~g}$. and melted at $84^{\circ}$ (corr.). When mixed with an equivalent of cis-camphonolic methyl ether the melting point as previously indicated was about $50^{\circ}$, showing that the two are different. The rotation for a solution in absolute alcohol containing $0.0844 \mathrm{~g}$. $/ \mathrm{cc}$. was $\alpha_{\mathrm{D}}^{299^{\circ}}=69.9^{\circ}$.

Lauronolic Acid.-This acid was prepared from $d$-camphoric anhydride according to the method of Aschan. ${ }^{2}$ The anhydride melted at $216^{\circ}$ (uncorr.) or $222^{\circ}$ (corr.). In the steam distillation of the acid it was noticed that the liquid became clear a long time before the distillate did. The lauronolic acid boiled constantly at $\mathrm{I} 39-140^{\circ}$ ( $\mathrm{I} 7 \mathrm{~mm}$.) and gave a rotation of $\alpha_{\mathrm{D}}^{25.5^{\circ}}=19 \mathrm{I}^{\circ}$. For a solution in absolute alcohol containing $0.04535 \mathrm{~g} . / \mathrm{cc}$., $\alpha_{\mathrm{D}}^{25^{\circ}}=152^{\circ}$. The refractive index was, $n_{\mathrm{C}}^{25^{\circ}}=$ I.47689; $n_{\mathrm{D}}^{25^{\circ}}=\mathrm{I} .47922 ; n_{\mathrm{F}}^{25^{\circ}}=\mathrm{I} .4865^{2} ; n_{\mathrm{G}^{\prime}}^{25^{\circ}}=\mathrm{I} .49298$. The bromolactone after repeated crystallization from hot ligroin melted constantly

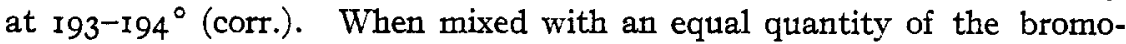
lactone from the unsaturated acid the melting point was $193-194^{\circ}$. It also gave the same campholactone and the same hydroxy acid. The rotation of the bromolactone was $\alpha_{\mathrm{D}}^{25^{\circ}}=51.0^{\circ}$ for a solution in absolute alcohol containing $0.04592 \mathrm{~g} . / \mathrm{cc}$.

Four and five-tenths grams of the acid upon distilling a second time from zinc chloride, washing with sodium hydroxide solution and drying with calcium chloride gave $0.9 \mathrm{~g}$. of laurolene boiling at $118-122^{\circ}$. The refractive index was $n_{\mathrm{C}}^{25^{\circ}}=1.43972 ; n_{\mathrm{D}}^{25^{\circ}}=\mathrm{I} .44315 ; n_{\mathrm{F}}^{220^{\circ}}=1.44988$; $n_{\mathrm{G}^{\prime}}^{25^{\circ}}=\mathrm{I} .45555$.

Structure of Isoaminocamphonanic Acid.-The optical rotation of isoaminocamphonanic acid and a series of compounds derived from it has

${ }^{1} \mathrm{Am}$. Chem. J., 35, 381 (1906).

2 Ber., 27, 3504 (1894). 
been taken to supplement Noyes and Potter's ${ }^{1}$ work on the valence of nitrogen in ammonium salts. Being a trans-amino acid it would not be expected to form an inner salt and the data appears to confirm this view. Isoaminocamphonanic acid.
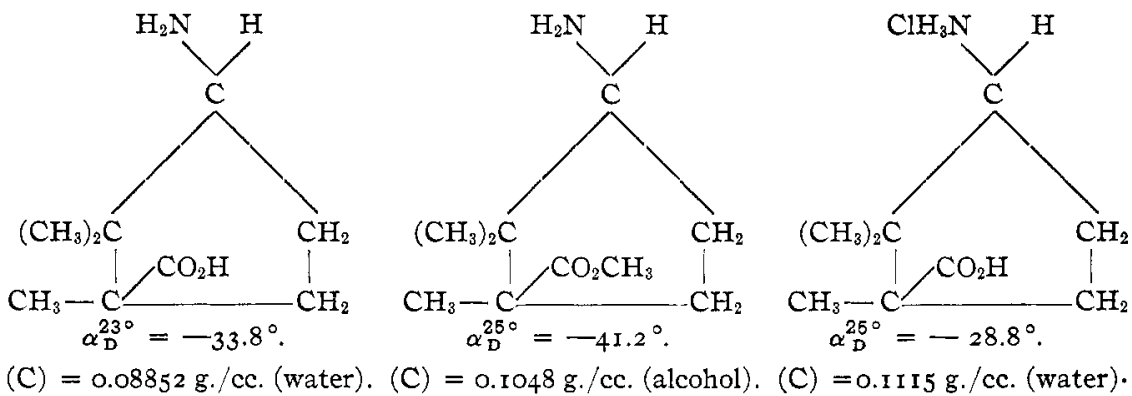

(C) $=0.08852 \mathrm{~g} . / \mathrm{cc}$ (water).

(C) $=0.1048 \mathrm{~g} . / \mathrm{cc}$. (alcohol)

(C) $=0.115 \mathrm{~g} . / \mathrm{cc}$. (water) .
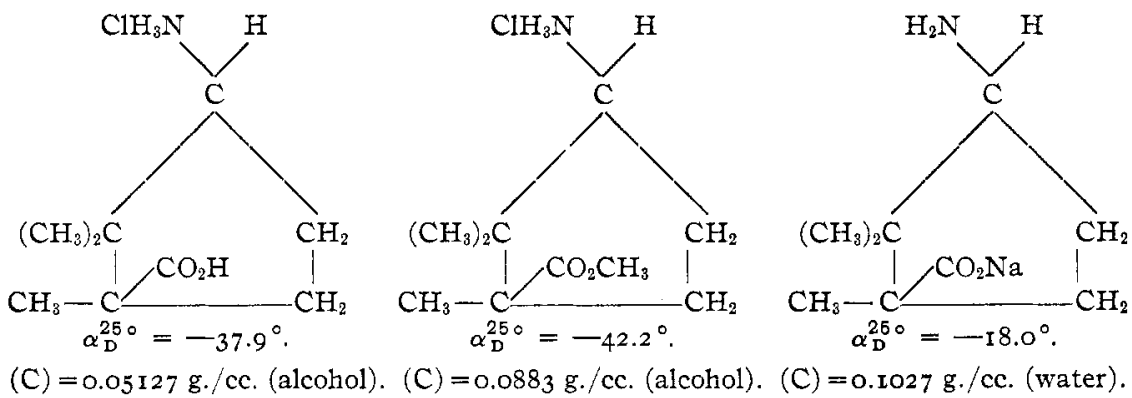

(C) $=0.05127 \mathrm{~g} . / \mathrm{cc}$. (alcohol)

(C) $=0.0883 \mathrm{~g} . / \mathrm{cc}$. (alcohol)

(C) $=0.1027 \mathrm{~g} . / \mathrm{cc}$. (water)

All of these compounds have a negative rotation, indicating that the isoaminocamphonanic acid forms no cyclic, inner salt. It will be recalled that the rotation of aminocamphonanic acid, which is a cis-compound indicates that it forms a cyclic salt.

\section{Summary.}

I. The method of preparation of methyl isoaminocamphonanate has, been improved and its physical constants have been determined.

2. In the nitrite decomposition the methyl esters of two unsaturated acids, the methyl ether of a hydroxy acid and the methyl esters of at least three hydroxy acids are formed. The methyl esters of the unsaturated acids cannot be separated by fractional distillation, nor can the free acids. No hydrocarbon is formed. The various compounds form the following percentages of the total weight of the products:

Methyl ether of cis-camphonolic acid............ $13 \%$

Methyl ester of cis-camphonolic acid............. $27 \%$

Esters of other hydroxy acids................ $20 \%$

Methyl esters of unsaturated acids ............. $40 \%$

1 This Journal, 37, I89 (I915). 
3. Lauronolic acid was identified by conversion to laurolene, preparation of the calcium salt, conversion to nitro-campholactone, conversion to campholactone, and conversion to the bromolactone. The bromolactone by saponification gives a dihydroxy acid melting at $172-173^{\circ}$ (uncorr.).

4. The new unsaturated acid forms $5-10 \%$ of the total weight of the unsaturated acids. Its structure has been proven by oxidation to an inactive tribasic acid which decomposes giving carbon dioxide when heated to its melting point.

5. The ether acid is the methyl ether of cis-camphonolic acid since it gives cis-camphonololactone by treatment with hydrogen iodide and has been synthesized from cis-camphonolic acid by treating the silver salt with methyl iodide.

6. One of the methyl esters is that of cis-camphonolic acid, which was identified by its physical constants, conversion to cis-camphonololactone, and oxidation to camphonanic acid.

7. The evidence that the crystalline hydroxy acid melting at IOI-IO ${ }^{\circ}$ is $1,2,3$-trimethyl-2-cis-hydroxy-I-cyclopentanoic acid is as follows:

(a) It is not oxidized by Beckmann's chromic acid mixture in the cold and does not give a lactone by this treatment.

(b) It gives a comparatively stable crystalline iodide, which gives lauronolic acid and no lactone when treated at once with sodium hydroxide solution.

(c) Its rotation is even more strongly positive than that for cis-camphonolic acid.

The fact that the rotation is positive points to the cis-configuration and the conduct toward chromic acid shows that the hydroxyl is tertiary. This hydroxyl must be either on the $\beta$ - or $\gamma$-carbon in order for it to give lauronolic acid through the iodide. Since it gives no lactone the hydroxyl must be on the $\beta$-carbon.

8. The remaining hydroxy acid probably contains a secondary $\beta$-hydroxyl since it is readily oxidized giving in part carbon dioxide and a volatile ketone. It has not been obtained free from the acid melting at ror$102^{\circ}$.

9. The ether acid from isocampholactone has been shown to be different from the methyl ether of cis-camphonolic acid.

Io. No ether acid is formed in the nitrite decomposition of aminocamphonanic or aminodihydrocampholytic acids.

I I. Additional evidence has been obtained in support of the view that the cis-amino acids of this series form inner salts, as the rotations of isoaminocamphonanic acid and certain of its derivatives indicate that no inner salt is formed.

I2. The formation of cis-camphonolic acid from the trans-isoamino- 
camphonanic acid is similar to the formation of trans-hydroxydihydroaminocampholytic acid from the cis-dihydroaminocampholytic acid.

The investigation will be continued.

URBANA, ILL.

\section{AN EFFICIENT APPARATUS FOR FRACTIONAL DISTILLATION UNDER DIMINISHED PRESSURE.}

By William A. Noyes and GlenN S. Skinner.

Received September 4, 1317.

As indicated in the preceding article we have devised a simple apparatus for the fractionation of the methyl esters formed in the decomposition of

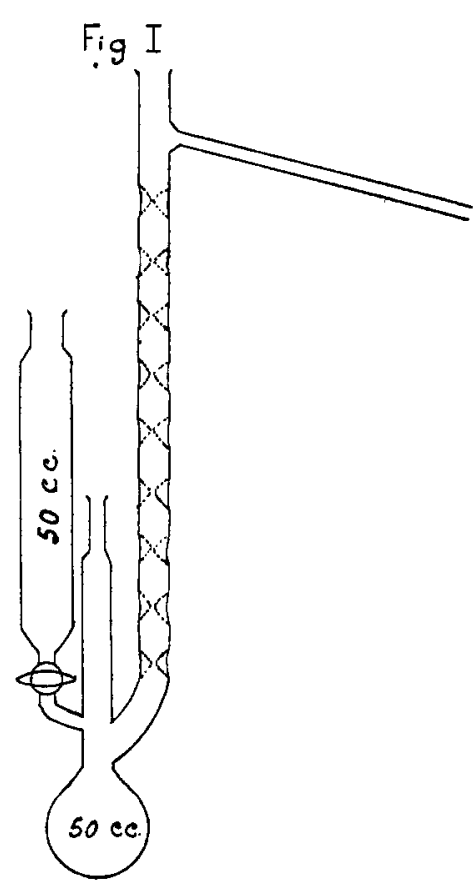
methyl isoaminocamphonanate with nitrous acid. We have found the apparatus so convenient and effective that it seems worth while to describe it.

It may be easily made from apparatus ordinarily found in the chemical laboratory, the essential parts being a separatory funnel, a Claissen bulb and a fractionating column. The apparatus, as may be seen from the diagram, offers the advantages: (I) that it may be used advantageously with either small or large fractions of material by regulating the flow of the entrant fraction from the funnel, and (2) that the successive fractions may be introduced without losing the vacuum. In case bulbs are used as receivers a wide mouth stopcock may be introduced into the side tube to serve the second purpose. The fractionating column may be made from tubing of convenient size by softening the glass at the proper points in the small flame of a blast lamp and indenting with the point of an iron wire. ${ }^{1}$ The points thus made should almost touch, and each successive pair of indentations should be at right angles to the preceding. The column used in our apparatus had 34 pairs of indentations in a length of $25 \mathrm{~cm}$.

In order to give some idea of the efficiency of the apparatus a portion of the data for one fractional distillation is given in Table I.

1 This form of a fractionating tube was first seen by one of us in the laboratory of Sir William Ramsay. 